\section{Wirksamkeitsnachweis bei Birkenallergien}

In einer doppelblinden plazebokontrollierten Studie wurde jetzt auch der Wirksamkeitsnachweis für Depigoid ${ }^{\circledR}$ bei Birkenallergikern anhand von Parametern erbracht, die die Zulassungsbehörden anerkennen. Bei starker Pollenbelastung zeigte sich in der zweiten Saison eine $50 \%$ ige Reduktion des kombinierten Symptom-Medikations-Score (SMS) im Vergleich zu Placebo. Damit wurden die Malling-Kriterien übertroffen, wonach das Verum wenigstens 30\% stärker als das Plazebo sein soll. In die Studie waren insgesamt 184 Patienten (über 18 Jahre) mit einer Allergie auf Baumpollen mit und ohne Asthma eingeschlossen. 137 wurden mit Depigoid ${ }^{\circledR}$ Frühblüher-Mix behandelt, 47 mit Placebo.

Nach Presseinformationen von Novartis

\section{Lippenpflege bei trockener Haut}

Wenn die Lippen und angrenzende Hautareale durch Kälte, Trockenheit oder Neurodermitis gereizt und gerötet sind, sollten sie zunächst vor allem mit entzündungshemmenden Mitteln wie z.B. Eucerin ${ }^{\circledR}$ Acute Lip Balm gepflegt werden. Auf rissige Lippen einen reinen Fettstift aufzutragen verbessert nur kurzfristig die subjektive Wahrnehmung, hilft aber nicht gegen die beginnende Entzündung. Wenig sinnvoll ist die Verwendung lange haftender Lippenstifte, weil sie die Haut zusätzlich austrocknen können.

Nach Informationen von Beiersdorf

\section{Optimierte Tuberkulosediagnostik}

Interferon-Gamma-Release-Assays (IGRA) sind Bluttests, die in der Tuberkulose-Diagnostik eine moderne, zuverlässige Alternative zu dem 110 Jahre alten Tuberkulin-Hauttest darstellen. Mit Wirkung zum 1. Januar 2011 erteilte die KBV IGRAs die Vergütungsziffer 32670 zur Durchführung von Tuberkulosetests, z.B. mit dem QuantiFERON-TB Gold (OFT), bei Patienten mit chronisch-entzündlichen, immunmodulierenden Erkrankungen vor einer Behandlung mit TNF-alpha-Inhibitoren. Weitere (englischsprachige) Informationen unter www.cellestis.com

Nach Informationen von Cellestis

\title{
Speziell entwickelte Spritze zur praktischen BTX-A-Anwendung
}

\begin{abstract}
- Ob Botulinumtoxin A oder moderne Filler - die Möglichkeiten in der minimalinvasiven Dermatologie sind so vielfältig wie die individuellen Gesichtszüge und ihre Veränderungen im Alter. Seit 2009 steht dem ästhetischen Dermatologen dazu das BTX-A-Präparat Azzalure ${ }^{\circledR}$ zur Verfügung, dass für die Behandlung mittelstarker bis starker Glabellafalten zugelassen ist.

Wirksamkeit und Verträglichkeit des Präparats wurden vor der Zulassung anhand vielfältiger Studien geprüft: Die gute Wirkung konnte allein durch neun randomisierte doppelblinde kontrollierte Studien belegt werden. So betrug die von den Prüfärzten beurteilte Ansprechrate 30 Tage nach der Behandlung bei maximaler muskulärer Anspannung 76-90\%. Unter BTX A wurde über mindestens vier Monate nach der Injektion eine signifikant höhere Ansprechrate beobachtet als unter Placebo $(p<0,005)$. Auch der schnelle Wirkeintritt von zwei bis vier Tagen sowie die lang anhaltende Wirkung überzeugten: Die mediane Ansprechdauer wurde in den acht prospektiven Studien auf 85-117 Tage geschätzt, in der retrospektiven Stu-
\end{abstract}

die wurde ein Behandlungsintervall von 5,9-6,5 Monaten dokumentiert.

Eine speziell von Galderma entwickelte Spritze mit einer Skalierung in Speywood Units (S.E) zur Anwendung in der Ästhetik macht die bisherige Umrechnung von BTXA-Einheiten in ml unnötig. Die 1-ml-Spritze wurde für 125 S.E. Füllvolumen mit Skalierungen von 10 S.E. und o,01 $\mathrm{ml}$ konzipiert. Auf die Spritze wird für die Rekonstitution eine $21 \mathrm{G} / 40 \mathrm{~mm}$-Kanüle und für die Injektion eine $30 \mathrm{G} / 13 \mathrm{~mm}$-Kanüle aufgesetzt. Die Rekonstitution des lyophilisierten BTX A (je 125 S.E. Azzalure ${ }^{\circledR}$ pro Durchstechflasche) erfolgt mit o,63 $\mathrm{ml}$ steriler und konservierungsmittelfreier physiologischer Kochsalzlösung auf eine abschließende Konzentration von 200 S.E./ml (oder 10 S.E./O,05 ml). Die Kochsalzlösung wird durch ein partielles Vakuum in die Flasche gezogen. Diese sollte leicht gedreht (nicht geschüttelt) werden, bis sich das weiße Pellet vollständig gelöst hat. Um einen Produktverlust zu vermeiden und die Lösung leicht aufzuziehen, sollte das Vakuum danach durch Abnehmen der Spritze kurz gelöst werden.

red

Nach Informationen von Galderma

\section{Forschungspreis zum Thema „Hautalterung“}

\begin{abstract}
— SARA steht für Skin Aging Research Award. Der Preis wird an Forschungsarbeiten verliehen, die fundamentale Bedeutung für die Pathogenese, Prävention oder Therapie in der Hautalterung haben. SARA wird unterstützt von La Roche-Posay - Laboratoire Dermatologique Deutschland und besteht aus einem Forschungspreis für einen etablierten Forscher von $15.000 €$ und einem Nachwuchs-Forschungspreis von 5.000, €. Deadline für die Einsendung der Arbeiten ist der 15. Februar 2011. Die Ausschreibungsunterlagen sind erhältlich bei: La Roche-Posay Laboratoire Dermatologique, Dr. med. Irene Rosengarten, Georg-Glock-Str. 18, 40474 Düsseldorf, Tel.: (O2 11) 4378148 E-Mail: irosengarten@de.loreal.com.
\end{abstract}

Nach Informationen von La Roche-PosayLaboratoire Dermatologique

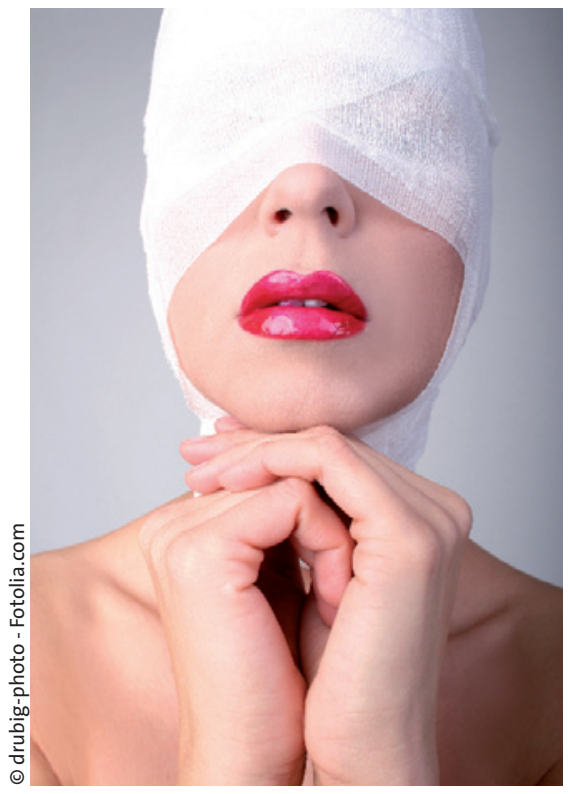

